\title{
BEHAVIOUR OF DIFFERENT PAVEMENT TYPES UNDER TRAFFIC LOADS USING FINITE ELEMENT MODELLING
}

\author{
Farag Khodary \\ Qena Faculty of Engineering south valley university - Qena, Egypt \\ Hesham akram \\ Qena Faculty of Engineering south valley university - Qena, Egypt \\ Nuha Mashaan \\ Faculty of Science and Engineering, Curtin University, Bentley WA 6102, Australia.
}

\begin{abstract}
Finite Element Modelling (FEM) has become an increasingly popular method to help researchers find solutions to complex problems of structural mechanics in engineering. Pavement is a complex structure which consists of multiple layers of different materials that influence its behaviour under stress. Rutting behaviour can be predicted by $3 D$ model analysis using the ABAQUS program. The modelling process assumes that the performance of all materials is one of linear elastic behaviour. The main inputs in the modelling process are the material elastic modulus, Poisson's ratio and layer thickness. Models consist of surface, base, subbase and subgrade layers. Subgrade layers are assumed to have infinite depth in all pavement models. This study employed a simulation process of rigid, semi-rigid and flexible pavements using a standard axle load of $80 \mathrm{kN}$, which represents a single two-wheeled axle. FEM analysis showed that instantaneous vertical displacement along the Z-axis reached $0.105 \mathrm{~mm}$, $0.32 \mathrm{~mm}$ and $0.66 \mathrm{~mm}$ for rigid, semi-rigid and flexible pavements respectively. Increasing the subgrade elastic modulus from $10 \mathrm{MPa}$ to $200 \mathrm{MPa}$ decreased the vertical displacement by seven, six and a half, and three and a half times for rigid, semirigid and flexible pavement respectively. KENLAYER results refer to the maximum vertical displacements as being 0.1, 0.28 and $0.60 \mathrm{~mm}$ for rigid, semi-rigid and flexible pavement respectively. The subgrade elastic modulus is key to improving the resistance to failure of all pavement types. Incremental increase to the subgrade elastic modulus is a potential engineering solution to reducing vertical displacement.
\end{abstract}

Keywords: Rigid Pavement, ABAQUS, Vertical Surface Displacement, Numerical Analysis, Permanent Deformation 
Cite this Article: Farag Khodary, Hesham akram and Nuha Mashaan, Behaviour of Different Pavement Types Under Traffic Loads Using Finite Element Modelling, International Journal of Civil Engineering and Technology, 11(11), 2020, pp. 40-48. https://iaeme.com/Home/issue/IJCIET?Volume=11\&Issue=11

\section{INTRODUCTION}

The road network is the system of arteries for transporting people and goods between villages, cities and countries around the world. A key component of this network is pavement, which takes various forms, such as flexible, semi-rigid and rigid pavement. Flexible pavement has several advantages, including low construction cost and widespread availability of construction materials (granular material and bituminous binders); hence why it is the most common pavement type around the world. Flexible pavement normally consists of many layers, such as the surface, base and subbase layers and the subgrade (foundation) soil. The combination of several flexible pavement layers is the key to increasing its load resistance. Flexible pavement is at risk of deformation under loads. Traffic loads directly affect the surface layer and are transferred to the bottom layers by particle friction. The effect of traffic loads decreases from the surface layer to the foundation soil. The surface layer is formed from one or more layers of asphalt mixture according to design requirements. The asphalt is exposed to higher stress than the lower layers, therefore it is stiffer and is the main source of strength of the pavement. The main function of the base and subbase layers is to decrease the stress upon the subgrade soil; therefore, the thickness of these layers depends on the strength of the subgrade soil. The main disadvantages of flexible pavements are weak resistance to temperature variation, high traffic loads and a requirement for periodic maintenance. Temperature variation is the most significant factor that affects flexible pavement deformation, as it affects the stiffness of the asphalt mixture and the unbound layers. An increase in temperature increases the negative impacts of strain, stress and surface deflection. Temperature variation also causes other distress, such as fatigue cracking, thermal cracking and rutting [1]. Traffic loads and environmental conditions (temperature variations) are the main causes of fatigue cracking [2]. Rigid pavements consist of concrete surface slabs with high strength, connected by tie bars or dowel steel bars. The traffic loads are distributed across a large area, which reduces the stress that is transferred to the lower layers, therefore reducing the number of lower layers that are required. Rigid pavement analysis is based on plate theory, which is a simplified version of layer theory. Plate theory is based on the assumptions that the concrete surface slab is a flat plane before and after loading. The design of pavements depends on many important factors, such as traffic volume and soil load-bearing capacity. Pavement design is based on the estimation of cumulative standard axels, to represent traffic load and the California Bearing Ratio (CBR) test, to evaluate the strength of the foundation soil.

Elastic modulus of material is the most important considerations in pavement design. Elastic performance of different materials that have high rigidity was measured using a resilient modulus (MR) test. MR is the soil mechanical reaction due to dynamic load cyclic application[3]. MR is used to indicate the strength of soil under pavement section, which is affected by soil properties (dry density and moisture content) and load characteristics, such as confining pressure and applied stress. MR is most importantly a primary input for pavement design, as the value expresses the modulus of subgrade reaction (K)[4]. The previous study of simulation pavement section refers to subgrade modulus which is considered an important factor to control the vertical movement in the surface of pavement compared with the effect of top layer modulus. Many pavement sections in 2D and 3D simulation are analysis by finite element programs such as ANSYS and ABAQUS. KENLAYER method can be useful in predicting pavement behaviour depending on different material performance such as linear, non-linear and visco-elastic behavior[5]. 


\section{METHODOLOGY}

\subsection{Pavement Structure under Study}

The pavement structure in the present study is composed of multiple layers of different materials, including the surface, base, subbase and subgrade layers. The asphalt surface layer is exposed directly to traffic loads and weather changes. With the passing of heavy vehicles, tangential stress occurs on the contact surface between the tyres and the asphalt layer. When vehicles brake or start moving suddenly, the friction between the wheels and the surface of the top layer causes erosion [6]. The base layer, under the surface asphalt layer, transfers and distributes the effect of traffic loads to the subbase layer. It consists of many types of materials such as crushed stone, aggregate, crushed slag and low-quality asphalt concrete mixture, therefore it is often called 'granular base'. The base layer must have a high hardness value and be free from harmful organic materials. It is considered to be the fixed foundation of the pavement following water spray and compaction treatment. The main function of the base layer is to support the surface asphalt layer in order to reduce the vertical stress transferred to the subbase layer. This protects the subbase layer from excessive stresses, which can lead to soil collapse and resists thermal stresses from daily and annual temperature changes. The subbase layer is considered an extension to the base layer, and complements its functionality in transferring stress to the subgrade layer. Stresses transferred to the subbase layer are lower than stresses on the base layer, so subbase materials have a lower quality than base layer materials. The subbase layer is used to prevent water leaking through the pavement section and to treat and adjust the surface before setting the base layer. It may be omitted when the natural soil is strong, or traffic loads are small. The materials used in the subbase layer must be free from harmful organic materials and be stable after compaction. The subbase layer consists of coarse soil that includes gravel, crushed river deposits and crushed stone. Subgrade is a natural soil layer that receives the traffic load from all the higher layers. The properties and moisture content of the subgrade layer have a direct effect on pavement performance. Most experimental work has proved that higher moisture content of the foundation soil, together with increased traffic volume, cause rapid deterioration of flexible pavement. Pavement analysis systems have confirmed that water seepage is the main cause of damage to pervious pavement structures. Moisture content, which is higher in clay soil, influences the behaviour of foundation soil. The properties of natural soil that does not conform to required specifications can be improved by using compaction or soil replacement methods, such as sand [7].
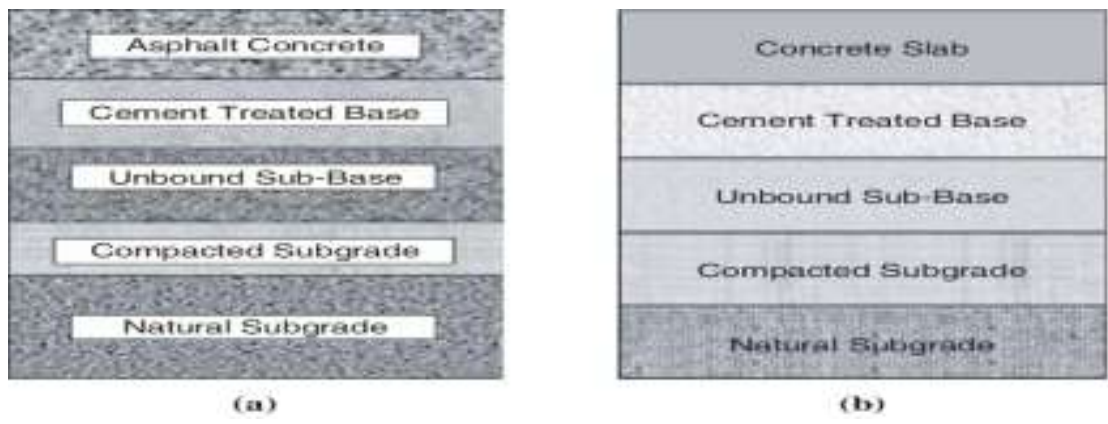

Figure 1 The Structures of Different Pavement Types: (a) Flexible; (b) Rigid [8].

\subsection{Model Geometry}

This study used the ABAQUS solid model to simulate pavement geometry, using discrete elements. Each element in the model represents a layer of pavement structure, such as concrete slab, lean concrete, granular subbase and subgrade. A 3D finite element was created based on a pavement section with symmetrical movement direction [9]. The vertical dimensions for the 
rigid pavement model were $26 \mathrm{~cm}, 31 \mathrm{~cm}$ and $15 \mathrm{~cm}$ for surface concrete slab, lean concrete and granular subbase respectively [10]. The natural foundation soil (subgrade) was defined as having infinite depth. The horizontal dimensions were $3600 \mathrm{~mm} \times 4000 \mathrm{~mm}$, which were assumed to avoid boundary value errors [11]. The displacement of all pavement model layers was controlled using specified boundary conditions. The finite element simulations depended on the presence of a subgrade layer that was not allowed to move either horizontally or vertically. Vertical displacement was permitted for surface concrete slab, lean concrete and granular subbase layers [12].

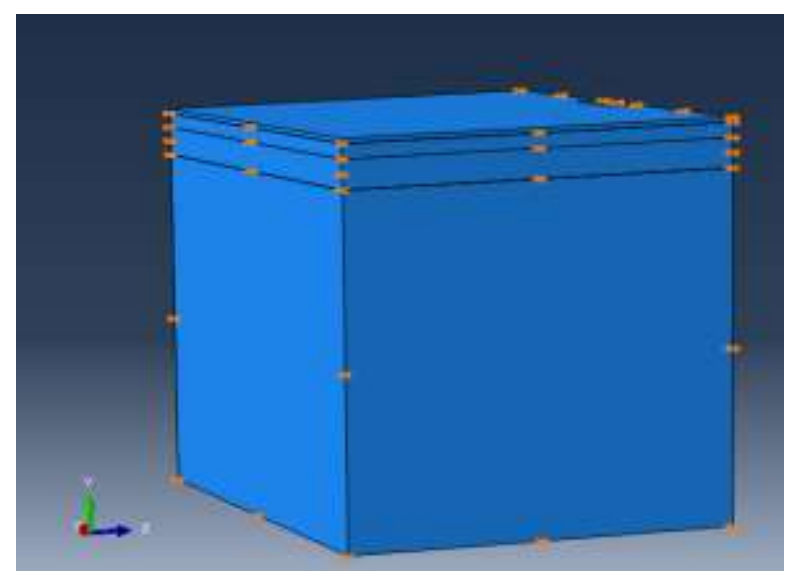

Figure 2 Finite Element Model Boundary Conditions.

\subsection{Finite Element Meshing}

The mesh module supports the creation of a mesh of the model, which is necessary for model analysis. Mesh density is a critical problem in FEM, as it is integral to the direct evaluation of the model's complexity level and the accuracy of analysis. The accuracy of FEM simulation and model complexity increases with use of a smaller mesh [13].

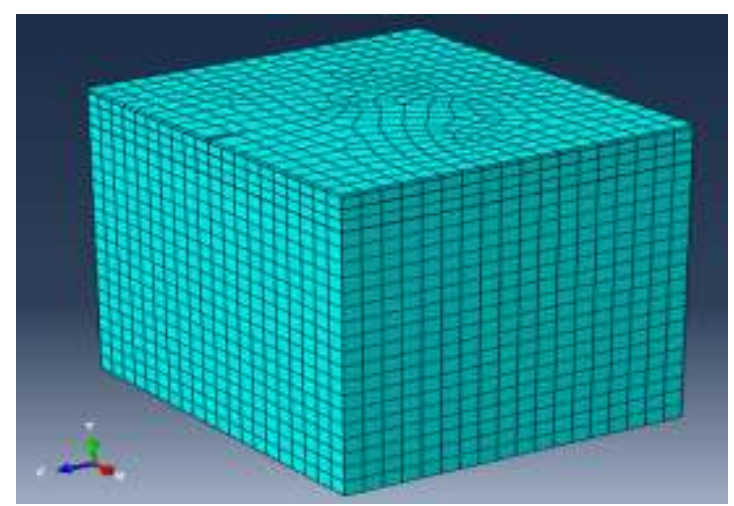

Figure 3 Finite Element Model Mesh.

\subsection{Load properties}

The simulation process for the pavement model was based on specifying the magnitude of the applied load as a pressure value, which represents the effect of a vehicle wheel during movement. Dynamic load was used to simulate the moving load, applied as a subjective function of time, as shown in equation (1):

$$
L(t)=\sin 2\left(\frac{\pi}{2}+\frac{\pi t}{d}\right)
$$

Where $\mathrm{d}=$ duration of the pulse in seconds [14]. 
The FEM assumed that the pressure of the vehicle wheel had a uniform distribution on the pavement. The standard axel, with a load magnitude of $80 \mathrm{kN}$, representing dual tyres with contact pressure of $0.6 \mathrm{MPa}$, was used to simulate the various traffic loads moving on the pavement [15]. The contact area between the surface concrete slab layer and the wheel during vehicle movement depends on tyre pressure; as tyre pressure decreases, the contact area increases. In general, the contact area has an irregular shape which consists of a middle rectangular part and two semi-circular side parts, as shown in equation (2).

$$
\text { Contact radius }(\mathrm{cm})=100 * \sqrt{\frac{\text { Load on single wheel }(\mathrm{KN})}{\pi * \operatorname{tire} \text { pressure }(\mathrm{kpa})}}
$$

\subsection{Material Properties}

The model analysis was based on the assumption that all the material layers of the model have linear elastic behaviour. Linear elastic theory is widely used in structural analysis of pavements. The essence of the theory is that there is a linear relationship between stress and strain, therefore a general relationship between stress and strain was represented in matrix form, as shown in equation (3):

$$
\left[\begin{array}{c}
\sigma_{11} \\
\sigma_{22} \\
\sigma_{33} \\
\sigma_{12} \\
\sigma_{23} \\
\sigma_{13}
\end{array}\right]=\frac{\mathrm{E}}{(1+\mathrm{v})(1-2 \mathrm{v})}\left[\begin{array}{cccccc}
1-\mathrm{v} & \mathrm{v} & \mathrm{v} & 0 & 0 & 0 \\
\mathrm{v} & 1-\mathrm{v} & \mathrm{v} & 0 & 0 & 0 \\
\mathrm{v} & \mathrm{v} & 1-\mathrm{v} & 0 & 0 & 0 \\
0 & 0 & 0 & \frac{1-2 \mathrm{v}}{2} & 0 & 0 \\
0 & 0 & 0 & 0 & \frac{1-2 \mathrm{v}}{2} & 0 \\
0 & 0 & 0 & 0 & 0 & \frac{1-2 \mathrm{v}}{2}
\end{array}\right]\left[\begin{array}{c}
\varepsilon_{11} \\
\varepsilon_{22} \\
\varepsilon_{33} \\
\varepsilon_{12} \\
\varepsilon_{23} \\
\varepsilon_{13}
\end{array}\right]
$$

Where $\varepsilon$ is predictable strain, $\sigma$ is applied stress, E is Young's modulus and v is Poisson's ratio [16].

\section{RESULTS AND DISCUSSION}

The various types of traffic loading (structural loading) and environmental conditions, including various temperatures and amounts of water seepage, caused several distresses over the pavement life span. The ABAQUS program was used to predict performance for rigid, semirigid and flexible pavement types. The types of pavement and their material characteristics are shown in Tables 1, 2 and 3:

Table 1 Property of Rigid Pavement Layers.

\begin{tabular}{|c|c|c|c|}
\hline Layer & $\begin{array}{c}\text { Modulus of elasticity (E) } \\
(\mathrm{MPa})\end{array}$ & Poisson ratio & $\begin{array}{c}\text { Thickness } \\
(\mathrm{mm})\end{array}$ \\
\hline Surface slab & 7500 & 0.2 & 260 \\
\hline Granular base & 4500 & 0.22 & 310 \\
\hline Granular subbase & 2000 & 0.25 & 150 \\
\hline Subgrade & 80 & 0.35 & $\infty$ \\
\hline
\end{tabular}

Table 2 Properties of Semi-Rigid Pavement Layers.

\begin{tabular}{|c|c|c|c|}
\hline Layer & $\begin{array}{c}\text { Modulus of elasticity (E) } \\
\text { (MPa) }\end{array}$ & Poisson ratio & $\begin{array}{c}\text { Thickness } \\
(\mathbf{m m})\end{array}$ \\
\hline Surface layer & 2689 & 0.3 & 140 \\
\hline Granular base & 2000 & 0.22 & 150 \\
\hline
\end{tabular}


Behaviour of Different Pavement Types Under Traffic Loads Using Finite Element Modelling

\begin{tabular}{|c|c|c|c|}
\hline Layer & $\begin{array}{c}\text { Modulus of elasticity (E) } \\
(\mathbf{M P a})\end{array}$ & Poisson ratio & $\begin{array}{c}\text { Thickness } \\
(\mathbf{m m})\end{array}$ \\
\hline Granular subbase & 400 & 0.30 & 150 \\
\hline Subgrade & 60 & 0.35 & $\infty$ \\
\hline
\end{tabular}

Table 3 Properties of Flexible Pavement Layers.

\begin{tabular}{|c|c|c|c|}
\hline Layer & $\begin{array}{c}\text { Modulus of elasticity (E) } \\
(\mathbf{M P a})\end{array}$ & Poisson ratio & $\begin{array}{c}\text { Thickness } \\
(\mathbf{m m})\end{array}$ \\
\hline Surface slab & 278 & 0.3 & 220 \\
\hline Granular base & 200 & 0.22 & 300 \\
\hline Granular subbase & 100 & 0.30 & 200 \\
\hline Subgrade & 50 & 0.35 & $\infty$ \\
\hline
\end{tabular}

\subsection{Rigid Pavement}

Figure 4 displays the results of the simulation of a rigid pavement section under traffic loads. The ABAQUS stress-strain analysis shows that the maximum vertical displacement along the $\mathrm{Z}$-axis was $0.105 \mathrm{~mm}$. The maximum value of vertical stress was $600 \mathrm{kPa}$ at the effect point. The maximum values of major principal stress and intermediate principal stress were 43.3 and $108.38 \mathrm{kPa}$ respectively.

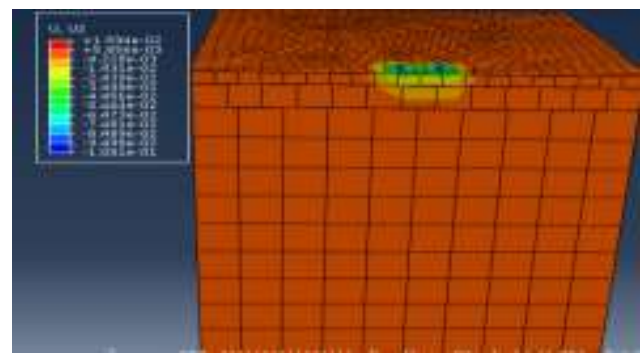

Figure 4 Results of the Stress-Strain Analysis for the Rigid Pavement Using ABAQUS Program.
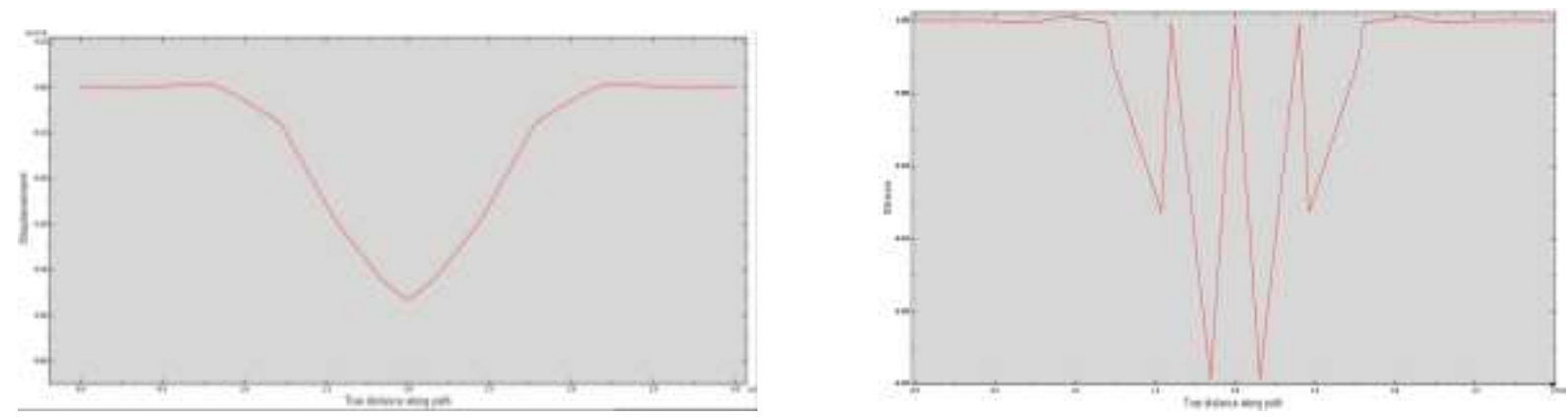

Figure 5 Rigid Pavement Subgrade Responses Using ABAQUS Program: (a) Subgrade Deflection, (b) Vertical Subgrade Stresses.

\subsection{Semi-Rigid Pavement}

Figure 6 shows the results of the ABAQUS stress-strain analysis for the semi-rigid pavement section. The maximum vertical displacement along the Z-axis was $0.32 \mathrm{~mm}$ at the point located between the dual wheels. The maximum values of vertical stress, major principal stress and intermediate principal stress were $600,161.72$ and $345.3 \mathrm{kPa}$, respectively. 


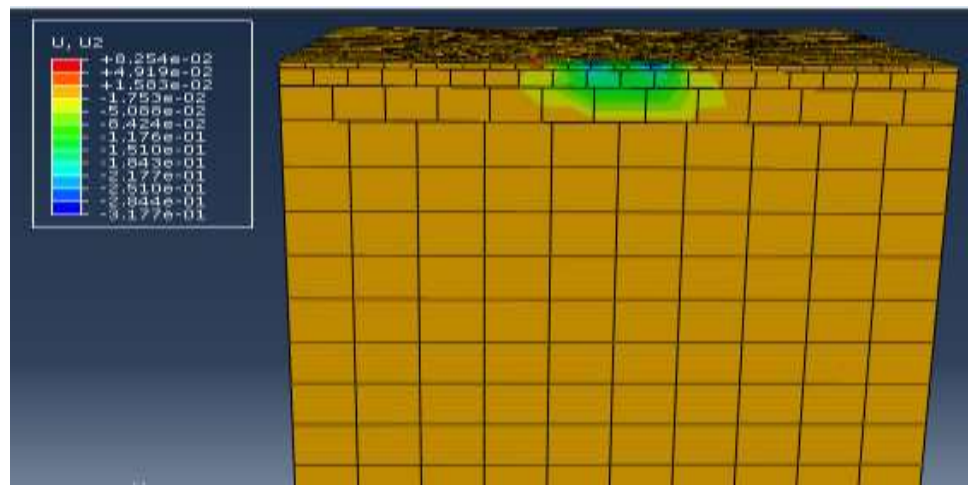

Figure 6 Results of the Stress-Strain Analysis for the Semi-Rigid Pavement Using ABAQUS Program

\subsection{Flexible Pavement}

Figure 8 illustrates the amount of rutting damage on the surface of flexible pavement model under traffic loads. The ABAQUS stress-strain analysis shows that the maximum vertical displacement along the $\mathrm{Z}$-axis was $0.66 \mathrm{~mm}$. The maximum values for vertical stress, major principal stress and intermediate principal stress at the surface of flexible section were 600 , 202.5 and $218.6 \mathrm{kPa}$, respectively.

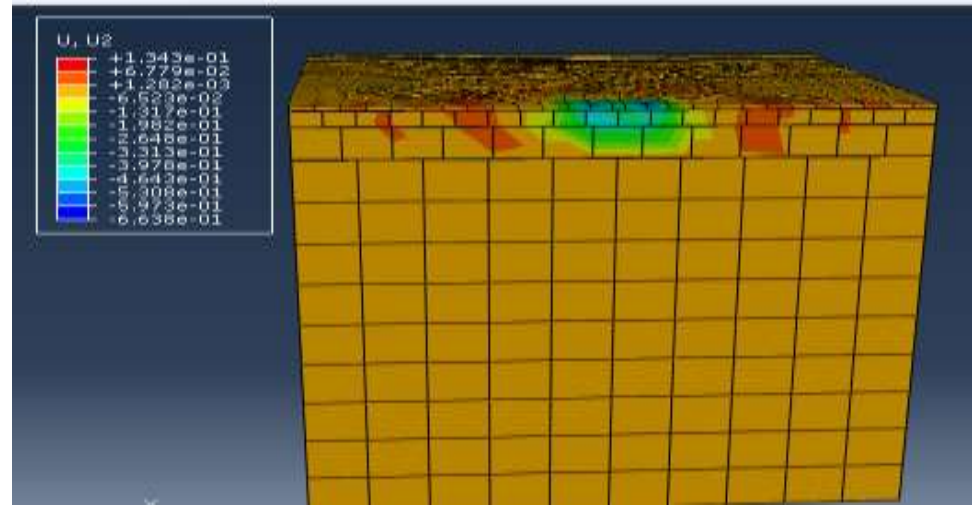

Figure 7 Results of the Stress-Strain Analysis for the Flexible Pavement Using ABAQUS Program.
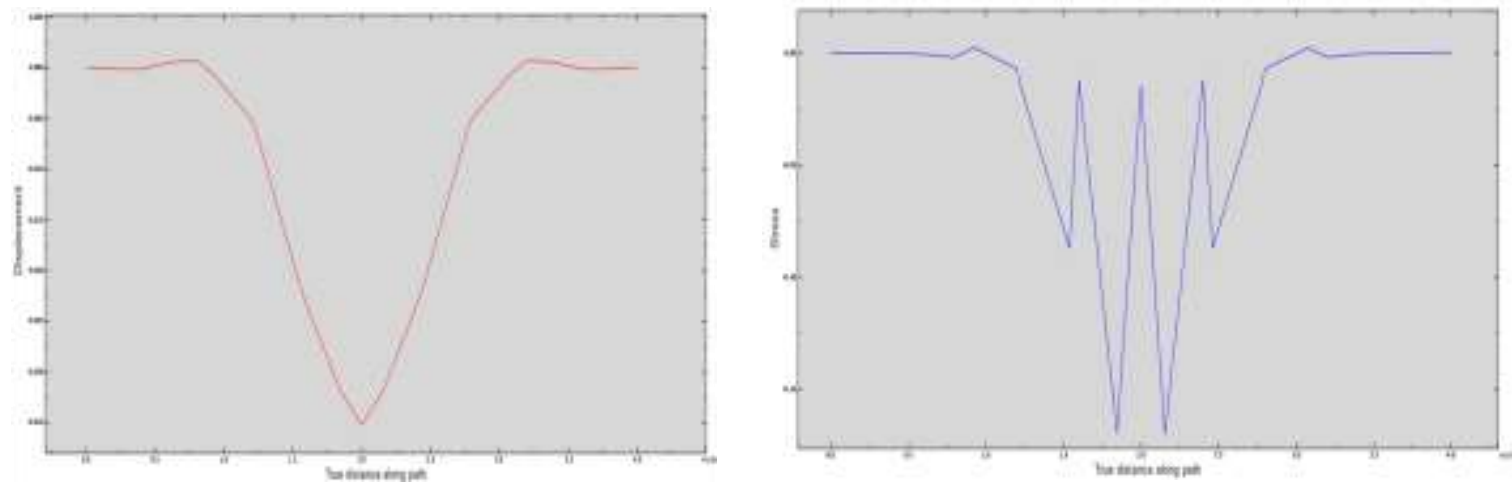

Figure 8 Flexible Pavement subgrade responses using ABAQUS program: (a) Subgrade deflection, (b) vertical subgrade stresses

\subsection{Effect of Subgrade Modulus}

The subgrade elastic modulus plays an important role in pavement performance and failure. To study the effect of the subgrade elastic modulus on vertical displacement along the $\mathrm{Z}$-axis, the subgrade layer elastic modulus was varied in increments from 10 to $200 \mathrm{MPa}$. The analysis of 
all pavement types showed that increasing the subgrade elastic modulus from $10 \mathrm{MPa}$ to 200 $\mathrm{MPa}$ decreased vertical displacement along the Z-axis, to the magnitude of seven, six and a half, and three and a half times for rigid, semi-rigid and flexible pavement respectively. The KENLAYER method indicates that increasing the subgrade elastic modulus from $10 \mathrm{MPa}$ to $200 \mathrm{MPa}$ decreases vertical displacement 6.5, 5.7 and 3 times for rigid, semi-rigid and flexible pavements, respectively.

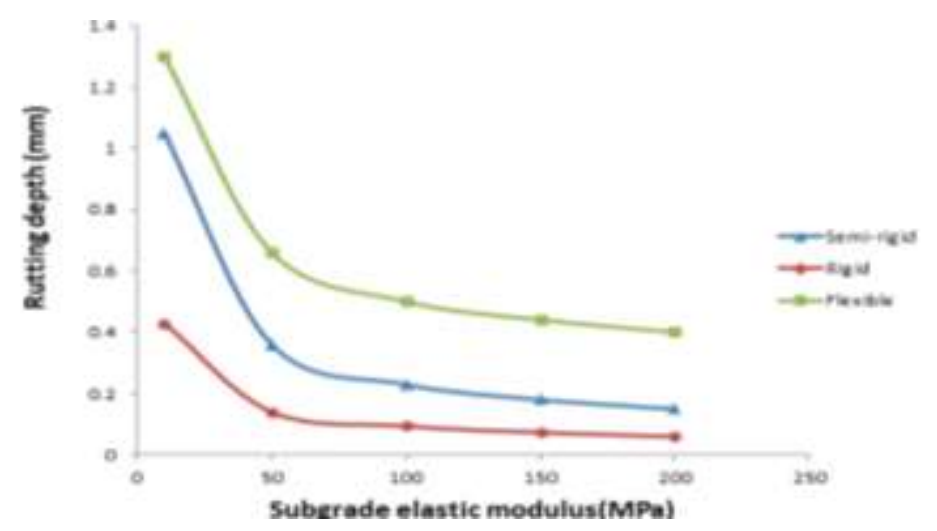

Figure 9 Effect of Subgrade Elastic Modulus on Different Types of Pavement Using ABAQUS

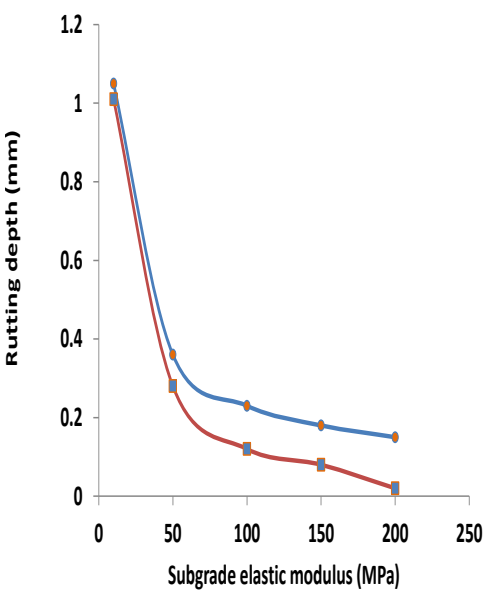

(b)

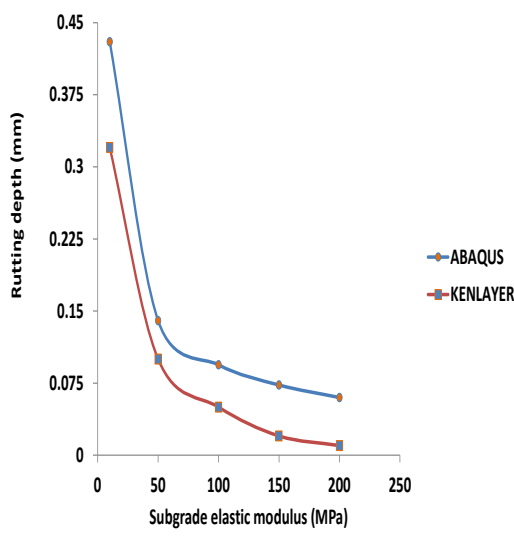

(a) Program.

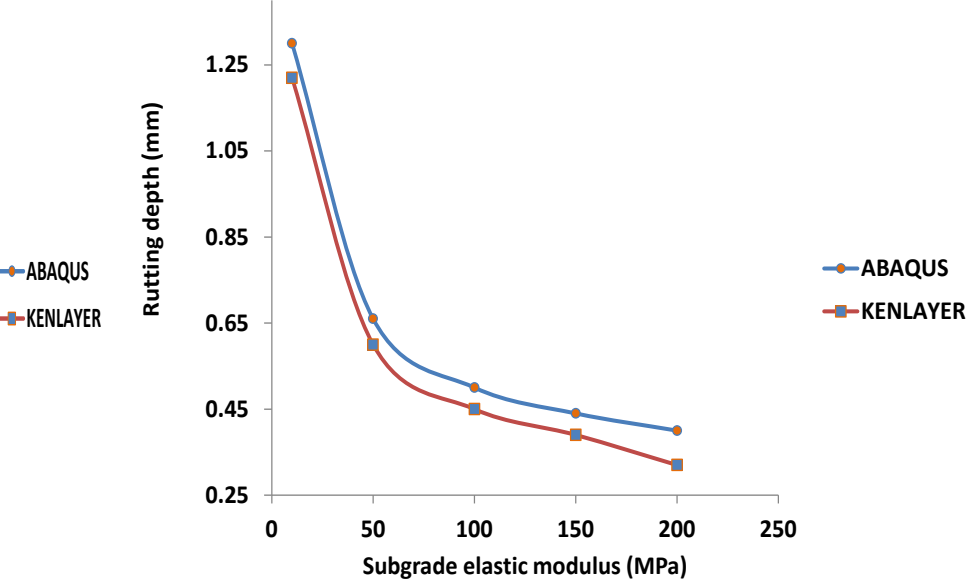

(c)

Figure 10 Compared Simulation Results from ABAQUS and KENLAYER for Effect subgrade Modulus: (a) Rigid Pavement, (b) Semi - rigid pavement, (c) Flexible Pavement

\section{CONCLUSIONS}

The analysis of results, based on previous theoretical studies of many types of pavement models, leads to several important considerations:

- FEM analysis indicated that the instantaneous vertical displacement along the Z-axis reached $0.105 \mathrm{~mm}, 0.32 \mathrm{~mm}$ and $0.66 \mathrm{~mm}$ for rigid, semi-rigid and flexible pavements, respectively.

- KENLAYER method refers to the maximum vertical displacements for the same pavement sections from rigid, semi-rigid and flexible pavements are $0.1,0.28$ and 0.60 mm respectively. 
- The maximum vertical deflections calculated from KENLAYER are low compared with the value obtained from ABAQUS program. Vertical displacement on the surface of the pavement model is sensitive to change in the elastic modulus of subgrade layer material.

- Incremental change to the subgrade elastic modulus is a potential engineering solution to reduce vertical displacement in all pavement types.

\section{REFERENCES}

[1] A. E. A. El-Maaty, "Temperature change implications for flexible pavement performance and life," International Journal of Transportation Engineering and Technology, vol. 3, pp. 1-11, 2017.

[2] Y. H. Dinegdae and B. Birgisson, "Effects of truck traffic on top-down fatigue cracking performance of flexible pavements using a new mechanics-based analysis framework," Road Materials and Pavement Design, vol. 19, pp. 182-200, 2018.

[3] A. J. L. M. Siang, D. C. Wijeyesekera, L. S. Mei, and A. Zainorabidin, "Innovative laboratory assessment of the resilient behaviour of materials (rigid, elastic and particulates)," Procedia Engineering, vol. 53, pp. 156-166, 2013.

[4] I. M. Ramadan, Z. S. E.-D. Hussein, and O. M. Mohamady, "EFFECT OF SOIL STRENGTHENING ON RIGID PAVEMENT THICKNESS," Journal of Al-Azhar University Engineering Sector, vol. 13, pp. 46-56, 2018.

[5] A. Gupta and A. Kumar, "Comparative structural analysis of flexible pavements using finite element method," International Journal on Pavement Engineering \& Asphalt Technology, vol. 15, pp. 11-19, 2014.

[6] S. Hou, X. Shi, Y. Deng, and F. Gu, "Evaluation of rutting and friction resistance of hot mix asphalt concrete using an innovative vertically loaded wheel tester," Construction and Building Materials, vol. 176, pp. 710-719, 2018.

[7] K. Hassan, L. Elghali, and C. Sowerby, Development of new materials for secondary and recycled aggregates in highway infrastructure: TRL Crowthorne, UK, 2004.

[8] P. Saxena, D. Tompkins, L. Khazanovich, and J. T. Balbo, "Evaluation of Characterization and Performance Modeling of Cementitiously Stabilized Layers in the Mechanistic-Empirical Pavement Design Guide," Transportation research record, vol. 2186, pp. 111-119, 2010.

[9] H. K. Shanbara, F. Ruddock, and W. Atherton, "Rutting prediction of a reinforced cold bituminous emulsion mixture using finite element modelling," Procedia engineering, vol. 164, pp. 222-229, 2016.

[10] M. Broutin and A. Sadoun, "Advanced modelling for rigid pavement assessment using HWD," Transportation Research Procedia, vol. 14, pp. 3572-3581, 2016.

[11] Z. A. Alkaissi, "Effect of high temperature and traffic loading on rutting performance of flexible pavement," Journal of King Saud University-Engineering Sciences, vol. 32, pp. 1-4, 2020.

[12] Z. A. Alkaissi and Y. M. Al-Badran, "FINITE ELEMENT MODELING OF RUTTING FOR FLEXIBLE PAVEMENT," Journal of Engineering and Sustainable Development, vol. 22, pp. $1-13,2018$.

[13] Y. Liu and G. Glass, "Effects of mesh density on finite element analysis," SAE Technical Paper 0148-7191, 2013.

[14] S. Pandey, H. Chowdary, and S. Rokade, "S: Effect of higher axle loads on service life of bituminous pavement," in CDROM Proceedings of World Conference and Asset Management, Milan (Baveno), 2017.

[15] A. H. Abed and A. A. Al-Azzawi, "Evaluation of rutting depth in flexible pavements by using finite element analysis and local empirical model," American Journal of Engineering and Applied Sciences, vol. 5, pp. 163-169, 2012.

[16] B. Ghadimi, H. Nikraz, and M. Rosano, "Dynamic simulation of a flexible pavement layers considering shakedown effects and soil-asphalt interaction," Transportation Geotechnics, vol. 7, pp. 40-58, 2016 